\title{
TITLE: Development of Keap1-interactive small molecules that regulate Nrf2 transcriptional activity
}

AUTHORS: Nikolaos D. Georgakopoulos ${ }^{1,2}$, Jemma Gatliff ${ }^{1,2}$, Geoff Wells ${ }^{1}$

ADDRESS: 'UCL School of Pharmacy, 29/39 Brunswick Square, London, WC1N 1AX, UK; ${ }^{2}$ Keregen Therapeutics Ltd, Stevenage Bioscience Catalyst, Gunnels Wood Rd, Stevenage SG1 2FX, UK.

Corresponding author: Geoff Wells, E: g.wells@ucl.ac.uk; T: 02077535935

\begin{abstract}
There has been considerable progress recently in the discovery and development of Keap1-interactive compounds that enhance Nrf2 transcriptional activity. The compounds fall into two broad classes: electrophilic cysteine-reactive compounds and nonelectrophilic Keap1-Nrf2 protein-protein interaction inhibitors. This short review highlights structures from both classes and discusses their development, biological properties and the future prospects for developing therapeutic agents. Molecules of both types have potential applications in areas including inflammatory conditions, chronic neurodegenerative diseases and possibly cancer chemoprevention.
\end{abstract}

\section{Introduction}

The activation of Nrf2 transcriptional activity has been highlighted as an attractive target for therapeutic intervention in a range of disease states spanning inflammatory and neurodegenerative conditions (including Parkinson's disease and Alzheimer's disease) and cancer chemoprevention [1]. Compounds that increase Nrf2 activity have therefore been sought as both chemical probes to evaluate the activity of Nrf2 in cells and as potential therapeutic agents. Most of the available compounds that increase Nrf2 activity do so by perturbing the behaviour of the ubiquitination facilitator protein Keap1 that targets Nrf2 for Cul3-mediated ubiquitination and destruction via a complex dynamic proteinprotein interaction (Figure 1). By stalling the ubiquitination process, the compounds increase the concentration of de novo synthesised Nrf2 within the cell and facilitate the expression of genes with Nrf2-responsive anti-oxidant response elements (AREs) in their promoter regions. In this review we will focus upon the two main groups of Keap1- 
interactive small molecules that up-regulate Nrf2 activity: those that modify cysteine residues and those that interact reversibly with the Keap1 $C$-terminal Kelch domain. We will also comment on the future potential of this therapeutic approach.

FIGURE 1.pptx

Figure 1. A and B. Schematic representation of the closed (A) and open (B) forms of the Keap1-Nrf2 complex. $C$ and D. Electrophilic inducers result in a closed form of the complex (C) and protein-protein interaction inhibitors an open form (D). Under resting conditions (A and B) Nrf2 is ubiquitinated (in form A) and free concentrations are kept at a low level. In the case of forms B, C, and D ubiquitination is stalled and Nrf2 accumulates in the cell and translocates to the nucleus $[2,3]$.

\section{Electrophilic inducers}

Keap1 contains several cysteine residues in its BTB domain and intervening region that sense electrophilic and redox stress within the cell [4], and the first Nrf2 inducers to be identified were cysteine-interactive electrophilic or redox-active compounds with broad ranging biological activity [5]. By covalently modifying cysteine residues in Keap1, these compounds are able to stall the ubiquitination of Nrf2, apparently by inducing the formation of a closed non-functional form of the Keap1-Nrf2 complex (Figure 1C) [2, 6].

\section{FIGURE 2.tiff}

Figure 2: A. Selected examples of electrophilic and pro-electrophilic Keap1 inhibitors; B. Modification of Keap1 cysteine thiols by Michael acceptors; C. Reaction of SFN with Keap1 cysteine thiols.

Electrophilic inducers have been described that are of natural, semisynthetic or synthetic origin (Figure 2A). Many are Michael acceptors that contain $\alpha, \beta$-unsaturated carbonyl functionality and undergo 1,4-addition with reactive Keap1 cysteine thiols (Figure 2B) [5]. Examples include the recently approved drug for multiple sclerosis, dimethyl fumarate 1 (Tecfidera $\AA^{8}$ ) [7], and the semisynthetic oleanolic acid derivative bardoxolone methyl 2 (CDDO-Me), which has been evaluated in clinical trials for the treatment of chronic kidney disease, pulmonary arterial hypertension and cancer [8]. Although both $\mathbf{1}$ and $\mathbf{2}$ have been shown to induce accumulation and nuclear translocation of $\mathrm{Nrf2}$ and subsequent activation 
of ARE-driven genes, their relative activities in vitro appear to differ considerably, with $\mathbf{2}$ being one of the most potent Nrf2 inducers identified to date [9].

The Nrf2-inducing activity of $\mathbf{1}$ is dependent on the modification of Keap1 Cys151, while on the other hand structural analogues of $\mathbf{2}$ appear to maintain their activity in cells expressing mutant Cys151S Keap1 [10]. However, a co-crystal structure of 2 covalently bound to Keap1 Cys151 within the BTB domain of Keap1 was recently reported, raising the possibility of a functional interaction with this site [11].

Curcumin 3, a bis-Michael acceptor, is a further example of a reactive Nrf2 inducer [5] that exhibits both in vitro and in vivo activity $[12,13]$. Despite its poor bioavailability, diverse biological activities and relatively low Nrf2-inducing potential [14], 3 has shown promising results in clinical trials for a plethora of different diseases [15]. tert-Butylhydroquinone 4 is an example of a pro-Michael acceptor that is bio-activated to form tert-butyl-p-quinone [16], which can undergo Michael addition reactions with reactive thiol groups [17]. It interacts with Cys151 of Keap1 and in contrast to 2, its Nrf2-inducing activity is greatly impaired in Cys151S Keap1-expressing cells compared to wild-type cells [10].

One of the most well-characterised Keap1 electrophilic inhibitors is the isothiocyanate natural product sulforaphane $\mathbf{5}$, which is derived from its glucosinolate precursor glucoraphanin, found in cruciferous vegetables, including broccoli and Brussels sprouts [18]. Several Keap1 cysteine residues have been reported as targets of 5 (Figure 2C) [19], however, its activity is highly dependent on Cys 151 both in vitro [20] and in vivo [21]. 5 is able to induce the nuclear accumulation of Nrf2 and subsequent transcription of its associated genes at mid-high nanomolar concentrations, exerting protective effects against inflammation and oxidative stress as well as reducing cancer cell proliferation and viability [18]. In addition, it has been evaluated in animal models and clinical trials for a plethora of diseases and degenerative conditions, including but not limited to several cancer types, diabetes and neurodegenerative conditions [18, 22-25].

Despite the interesting cellular activity of the various electrophilic inducers and their adoption as chemical probes to investigate Nrf2 in cellular processes and disease models [26], their reactive nature is problematic, resulting in a range of off-target effects [27]. 5 in particular has been shown to interact directly with a variety of redox-sensitive targets [28], leading to a complicated mode of action and several Nrf2-independent effects [29-32]. Molecules with a higher selectivity for Keap 1 could exhibit lower toxicity and have a better therapeutic profile, while in addition they would be more attractive chemical tools to probe 
the complex biology associated with the Keap1/Nrf2 pathway. In this respect the chemical properties of $\mathbf{2}$ are particularly interesting, because its cyano-enone moiety undergoes a reversible Michael-type reaction with cysteine residues. This raises the prospect of limiting off-target effects, because the reaction with cysteine residues is reversible, but promoting Keap1 interaction via complementary non-covalent interactions at the Keap1 binding site.

\section{Direct (non-covalent) Nrf2 inducers}

Despite the interesting biological activity of electrophilic Nrf2 inducers, direct non-covalent inhibition of the Keap1-Nrf2 protein-protein interaction (PPI) has been proposed as an alternative, more selective approach to increase Nrf2 activity [5, 27, 33]. Crystallographic (Figure 3B) and mutagenesis studies have shown that Nrf2 binds to Keap1 through relatively short sequences to a well-defined pocket within the Keap1 Kelch domain and this interaction is mediated mainly by the acidic residues of the ETGE and DLG Nrf2 motifs [34-36]. The interacting surface area between Keap1 and Nrf2 is relatively small and resembles a receptor-type interaction rather than a typical PPI, suggesting that the discovery of potent PPI inhibitors is possible [33].

A number of peptide ligands have been designed and evaluated [37-39]. Those based upon hybrid sequences derived from the high affinity Nrf2 (ETGE) binding sequence and the related p62 Keap1 interaction region yielded a high affinity 7 mer peptide, AcDPETGEL-OH ( $\left.\mathrm{IC}_{50}=116 \mathrm{nM}\right)$ [38] a related 11 mer peptide, Ac-CLDPETGEYLC-OH had a slightly higher affinity $\left(K_{d}=15.9 \mathrm{nM}\right)$ [39]. The cell permeability of these acidic peptides is quite poor although efforts to improve their biological activity through fatty acid [40] or TAT peptide conjugation [41] have had some success, generally yielding molecules with micromolar activity in Nrf2-dependent enzyme expression assays (NQO1 and HO1 respectively).

\section{Small molecules}

Following the success of peptide inhibitors of the Keap1-Nrf2 PPI in vitro several groups pursued small molecules that activate Nrf2 via this same mode of action (Figure 3A) [33]. Most of the initial hit compounds were identified using high-throughput screening approaches although rational design, fragment-based approaches and in silico methods have been used in recent discovery and lead optimisation studies. 
FIGURE 3A.tiff

FIGURE 3B-D.pptx

Figure 3. A. Selected examples of small molecule Keap1-Nrf2 PPI inhibitors; B. Crystal structure of an Nrf2 ETGE peptide bound to Keap1 (Nrf2 ETGE residues displayed) (PDB: 2FLU); C. Crystal structure of 10 bound to Keap1 (PDB: 4XMB); D. Crystal structure of 13 bound to Keap1 (PDB: 5FNU). The Keap1 Kelch domain is shown as a surface representation, peptides and small molecules in stick representation.

The first small molecule inhibitor to be described was the tetrahydroisoquinoline LH601A 6 [42], a compound originally identified as an HTS hit from the MLPCN screening library (337,116 compounds). The $(S, R, S)$ configuration of 6 was optimal for Keap1 binding ( $\mathrm{K}_{\mathrm{d}}$ $=1.0 \mu \mathrm{M}$, fluorescence polarisation assay) and it induced the nuclear translocation of Nrf2 in cells with an $\mathrm{EC}_{50}$ of $12 \mu \mathrm{M}$ [42]. The compound up-regulated NQO1, HO-1 and TRX1 at mid-high micromolar concentrations in HEK293 cells but had limited effect on glutathione-related genes [43]. Interestingly, in the same study, sulforaphane 5 enhanced levels of GCLC (glutamate cysteine ligase, catalytic), GCLM (glutamate cysteine ligase, modifier) and GSR (glutathione reductase) in addition to NQO1, HO-1 and TRX1. Structural insights into the binding behaviour of 6 were obtained from a co-crystal structure with Keap1, but significant improvements in binding affinity were difficult to achieve [44]. An analysis of the DMPK properties of 6 showed that it was restricted to the peripheral compartment, due in part to it being a P-gp substrate. Attempts were made to obtain in vivo brain exposure, but binding affinity was lost [44].

Two sulphonamide compounds were identified through an HTS screen conducted using the Evotec Lead Discovery library (267,551 compounds) supplemented with 1,911 compounds, previously identified by virtual screening [45]. The benzenesulfonyl pyrimidone 7 and the symmetrical naphthalene bis-sulfonamide 8 had $\mathrm{IC}_{50}$ values of 118 $\mu \mathrm{M}$ and $2.7 \mu \mathrm{M}$ respectively in a confocal fluorescence anisotropy assay. Compound 8 stabilised Nrf2 and up-regulated NQO1 expression at low-mid micromolar concentrations [45]. Attachment of acetate side chains to the sulfonamide nitrogen atoms of 8 had a profound effect on the overall activity of the compound series, yielding a symmetrical bisacid 9 with an $\mathrm{IC}_{50}$ of $28.6 \mathrm{nM}$ [46]. Molecular docking simulations demonstrated that the acetic acid moieties mimic the two glutamate side chains of the high-affinity ETGE motif of Nrf2 and interact with Arg483 and Arg415 in the Keap1 binding pocket. Cocrystallisation of a related bis-acetamide compound $\mathbf{1 0}$ confirmed the proposed binding 
mode (Figure 3C) [47]. Despite the presence of two ionisable groups, 9 was able to activate the expression of Nrf2-dependent gene products at low $\mu \mathrm{M}$ concentrations [46]. A follow-up study revealed that a $p$-acetamido analogue of $\mathbf{1 1}$ had improved solubility and cellular activity in an Nrf2-dependent ARE luciferase assay at concentrations as low as $100 \mathrm{nM}$. In vivo a dose of $10 \mathrm{mg} / \mathrm{kg}$ was sufficient to reduce the levels of inflammatory markers in an LPS-induced inflammation model without exhibiting acute toxicity (Table 1) [48].

The bis-sulfonamide structure has been de-symmetrised in several studies [47, 49], one of which resulted in RA839, 12 which inhibited the Keap1-Nrf2 PPI with an FP IC 50 of 140 $\mathrm{nM}$ and an ITC $\mathrm{K}_{d}$ of $6 \mu \mathrm{M}$. The compound had promising cell-based activity, but was found to be subject to oxidative metabolism, which hampered in vivo evaluation [49].

\begin{tabular}{|c|c|c|c|c|c|c|}
\hline Cpd & $\begin{array}{l}\text { Keap1 } \\
\mathrm{K}_{\mathrm{D}} \text { (ITC) }\end{array}$ & $\begin{array}{l}\text { Disease } \\
\text { model }\end{array}$ & Treatment & $\begin{array}{l}\text { Disease } \\
\text { relevance }\end{array}$ & Outcome & $\operatorname{Re}$ \\
\hline 6 & $39.8 \mathrm{nM}$ & $\begin{array}{l}\text { LPS-induced } \\
\text { model of } \\
\text { inflammation } \\
\text { (mouse) }\end{array}$ & $\begin{array}{l}10 \mathrm{mg} / \mathrm{kg} / \text { day or } \\
80 \mathrm{mg} / \mathrm{kg} / \text { day } \\
\text { for } 3 \text { days } \\
\text { before LPS } \\
\text { challenge }\end{array}$ & $\begin{array}{l}\text { Inflammatory } \\
\text { conditions }\end{array}$ & $\begin{array}{l}\text { Prophylactic treatment } \\
\text { relieves LPS-induced } \\
\text { inflammation: } \\
\downarrow \text { cytokine levels (TNF-a, } \\
\text { IFN- }, \text { IL-6, IL-12, IL-17) }\end{array}$ & {$[48$} \\
\hline 6 & $39.8 \mathrm{nM}$ & $\begin{array}{l}\text { DSS-induced } \\
\text { model of UC } \\
\text { (mouse) }\end{array}$ & $\begin{array}{l}10 \mathrm{mg} / \mathrm{kg} \text { or } 40 \\
\mathrm{mg} / \mathrm{kg} \text { (oral) } \\
\text { simultaneous } \\
\text { administration } \\
\text { with } 3 \% \mathrm{w} / \mathrm{v} \\
\text { DSS } 8 \text { days on } \\
8 \text { days off (x4 } \\
\text { cycles) }\end{array}$ & $\begin{array}{l}\text { UC, Crohn's } \\
\text { disease, } \\
\text { inflammatory } \\
\text { bowel } \\
\text { disease, } \\
\text { colorectal } \\
\text { cancer }\end{array}$ & $\begin{array}{l}\text { Protects against DSS- } \\
\text { induced damage: } \\
\text { elimination of inflammatory } \\
\text { cells, preserved colonic } \\
\text { structure, prevented of } \\
\text { lamina propria expansion, } \uparrow \\
\text { colonic GSH:GSSG ratio }\end{array}$ & {$[50$} \\
\hline 8 & $1.3 \mathrm{nM}$ & $\begin{array}{l}\text { Ozone }\left(\mathrm{O}_{3}\right)- \\
\text { induced rat } \\
\text { model of } \\
\text { pulmonary } \\
\text { inflammation }\end{array}$ & $\begin{array}{l}16.5 \mathrm{mg} / \mathrm{kg} \text { (iv) } \\
\text { for } 6 \text { hours } 24 \\
\text { hours before } \\
\text { ozone injury: } 1 \\
\text { ppm for } 3 \text { hours. }\end{array}$ & COPD & $\begin{array}{l}\text { Attenuation of pulmonary } \\
\text { inflammation: } \downarrow \text { levels of } \\
\text { inflammatory cells in the } \\
\text { bronchoalveolar fluid, } \\
\text { preserved levels of GSH, } \downarrow \\
\text { oxidative stress }\end{array}$ & {$[51$} \\
\hline 10 & NA & $\begin{array}{l}\text { CDDA rat } \\
\text { model of } \\
\text { NASH }\end{array}$ & $\begin{array}{l}6 \text { weeks pre- } \\
\text { feeding of } \\
\text { CDAA diet } \\
\text { followed by } 4 \\
\text { weeks } 60 \\
\mathrm{mg} / \mathrm{kg} / \text { day } \\
\text { administration }\end{array}$ & $\mathrm{NASH}$ & $\begin{array}{l}\text { Treatment prevented } \\
\text { progression of established } \\
\text { fibrosis in NASH model rats } \\
\text { liver: } \downarrow \text { fibrosis score, } \downarrow \% \\
\text { fibrosis area }\end{array}$ & {$[52$} \\
\hline
\end{tabular}

Table 1: In vivo disease model studies with Keap1-Nrf2 protein-protein interaction inhibitors. Notes: NA - data not available; LPS - lipopolysaccharide; DSS - dextran sodium sulfate; UC - ulcerative colitis; COPD - chronic obstructive pulmonary disease; CDDA - choline deficient, L-amino acid defined; NASH - non-alcoholic steatohepatitis. 
Recently, Astex and GSK identified a high affinity lead compound through a crystallographic fragment-based screen. Linkage of three fragments with orthogonal Keap1 binding behaviour followed by SAR-based optimisation yielded the mono acid $\mathbf{1 3}$ $\left(K_{d} 1.3 \mathrm{nM}\right)$ (Figure 3D). The compound induced the expression of a range of Nrf2 target genes (NQO1, HO1, glutamate-cysteine ligase, thioredoxin reductase-1) at low nanomolar concentrations. Subsequently the compound was shown to exert protective effects in an in vivo COPD model (Table 1) [51].

A further compound to emerge from Toray Industries was the urea derivative 14 [53]. Although its binding affinity for Keap1 has not been described, it has been co-crystallised with the Keap1 Kelch domain. The related pyridine derivative 15, although a relatively weak Keap1 ligand (Keap1-Nrf2 PPI inhibition > $50 \mu \mathrm{M}$ ), exerts protective effects in a rat model of non-alcoholic steatohepatitis (Table 1) [52].

Amongst the non-electrophilic Nrf2 inducers a class of 1,4-diphenyl-1,2,3-triazoles has been studied in detail with regard to their effects on cellular functions associated with mitochondrial autophagy (mitophagy) and Parkinson's disease. Prototype compounds such as 16 and 17 inhibit the Keap1-Nrf2 interaction in live cells and increase the expression of Nrf2 target genes [3]. A direct comparison between 17 and sulforaphane 5 indicated differences in cellular effects between the two types of inducer. In particular, 17 was able to promote mitophagy without an apparent effect on mitochondrial membrane potential or function, an activity that was partially independent of the PINK1/Parkin mitophagy pathway [54, 55]. 5 was less able to induce these effects, suggesting that there may be different therapeutic applications for non-electrophilic ligands, particularly in the area of Parkinson's disease where PINK1 and Parkin play a role in hereditary and early onset forms of the condition [56].

\section{Future perspectives}

There has been considerable recent progress in the development of compounds that induce Nrf2 activity for potential therapeutic applications. The high-potency bardoxolone methyl-type inducers are examples of promising electrophilic compounds with an intriguing reversible covalent binding mode. They have shown therapeutic efficacy in a range of disease settings although their therapeutic window and toxicities need further research after their recent failure in a phase 3 clinical study for chronic kidney disease 
[57]. Reversible inhibitors of the Keap1-Nrf2 PPI have been developed recently. Despite the difficulty of targeting protein-protein interactions, several structural classes of inhibitors have been identified that bind to Keap1 with high affinity. The potential for these compounds to exert different effects of Nrf2, both in magnitude and timescale, and different pharmacological effects on treated cells suggests that they may have a different range of therapeutic applications, particularly in the area of neurodegenerative diseases. However, in order to progress to in vivo studies for CNS applications the current pool of lead compounds will require further optimisation in order to achieve the physicochemical properties required for crossing the blood-brain barrier.

\section{Funding}

GW acknowledges Cancer Research UK (C9344/A10268), the BBSRC (BB/L01923X/1) and UCL School of Pharmacy for financial support.

\section{References}

[1] O'Connell MA, Hayes JD. The Keap1/Nrf2 pathway in health and disease: from the bench to the clinic. Biochem Soc Trans. 2015;43:687-9.

* A concise summary of the role of the Keap1-Nrf2-ARE axis in health and disease [2] Baird L, Lleres D, Swift S, Dinkova-Kostova AT. Regulatory flexibility in the Nrf2mediated stress response is conferred by conformational cycling of the Keap1-Nrf2 protein complex. Proc Natl Acad Sci U S A. 2013;110:15259-64.

** This study describes the dynamic interaction between Keap1 and Nrf2 in live cells, together with the mode of regulation by Nrf2 inducers.

[3] Bertrand HC, Schaap M, Baird L, Georgakopoulos ND, Fowkes A, Thiollier C, et al. Design, Synthesis, and Evaluation of Triazole Derivatives That Induce Nrf2 Dependent Gene Products and Inhibit the Keap1-Nrf2 Protein-Protein Interaction. J Med Chem. 2015;58:7186-94.

* The authors apply the methodolgy in [2] to indicate that non-electrophilic inducers of Nrf2 exert a different effect on the Keap1-Nrf2 interaction to electrophiles.

[4] Uruno A, Motohashi H. The Keap1-Nrf2 system as an in vivo sensor for electrophiles. Nitric Oxide. 2011;25:153-60.

[5] Magesh S, Chen Y, Hu L. Small molecule modulators of Keap1-Nrf2-ARE pathway as potential preventive and therapeutic agents. Med Res Rev. 2012;32:687-726.

[6] Baird L, Swift S, Lleres D, Dinkova-Kostova AT. Monitoring Keap1-Nrf2 interactions in single live cells. Biotechnol Adv. 2014;32:1133-44.

[7] Bomprezzi R. Dimethyl fumarate in the treatment of relapsing-remitting multiple sclerosis: an overview. Ther Adv Neurol Disord. 2015;8:20-30.

* This article summarises the development of dimethyl fumarate as a clinical agent for use in multiple sclerosis 
[8] Wang YY, Yang YX, Zhe H, He ZX, Zhou SF. Bardoxolone methyl (CDDO-Me) as a therapeutic agent: an update on its pharmacokinetic and pharmacodynamic properties. Drug Des Devel Ther. 2014;8:2075-88.

[9] Copple IM, Shelton LM, Walsh J, Kratschmar DV, Lister A, Odermatt A, et al. Chemical tuning enhances both potency toward nrf2 and in vitro therapeutic index of triterpenoids. Toxicol Sci. 2014;140:462-9.

[10] Takaya K, Suzuki T, Motohashi H, Onodera K, Satomi S, Kensler TW, et al. Validation of the multiple sensor mechanism of the Keap1-Nrf2 system. Free Radic Biol Med. 2012;53:817-27.

[11] Cleasby A, Yon J, Day PJ, Richardson C, Tickle IJ, Williams PA, et al. Structure of the BTB domain of Keap1 and its interaction with the triterpenoid antagonist CDDO. PLoS One. 2014;9:e98896.

** This article describes a co-crystal structure of CDDO with the BTB domain of Keap1, providing a structural basis for understanding this interaction.

[12] Balogun E, Hoque M, Gong P, Killeen E, Green CJ, Foresti R, et al. Curcumin activates the haem oxygenase-1 gene via regulation of $\mathrm{Nr} 2$ and the antioxidantresponsive element. Biochem J. 2003;371:887-95.

[13] Soetikno V, Sari FR, Lakshmanan AP, Arumugam S, Harima M, Suzuki K, et al. Curcumin alleviates oxidative stress, inflammation, and renal fibrosis in remnant kidney through the Nrf2-keap1 pathway. Mol Nutr Food Res. 2013;57:1649-59.

[14] Shen T, Jiang T, Long M, Chen J, Ren DM, Wong PK, et al. A Curcumin Derivative That Inhibits Vinyl Carbamate-Induced Lung Carcinogenesis via Activation of the Nrf2 Protective Response. Antioxid Redox Signal. 2015;23:651-64.

[15] Gupta SC, Patchva S, Aggarwal BB. Therapeutic roles of curcumin: lessons learned from clinical trials. AAPS J. 2013;15:195-218.

[16] Wilson AJ, Kerns JK, Callahan JF, Moody CJ. Keap calm, and carry on covalently. J Med Chem. 2013;56:7463-76.

[17] Satoh T, Okamoto SI, Cui J, Watanabe Y, Furuta K, Suzuki M, et al. Activation of the Keap1/Nrf2 pathway for neuroprotection by electrophilic [correction of electrophillic] phase II inducers. Proc Natl Acad Sci U S A. 2006;103:768-73.

* This article describes the potential role of Nrf2 inducing compounds in a neuroprotective context.

[18] Guerrero-Beltran CE, Calderon-Oliver M, Pedraza-Chaverri J, Chirino YI. Protective effect of sulforaphane against oxidative stress: recent advances. Exp Toxicol Pathol. 2012;64:503-8.

[19] Hu C, Eggler AL, Mesecar AD, van Breemen RB. Modification of keap1 cysteine residues by sulforaphane. Chem Res Toxicol. 2011;24:515-21.

[20] Zhang DD, Hannink M. Distinct cysteine residues in Keap1 are required for Keap1dependent ubiquitination of Nrf2 and for stabilization of Nrf2 by chemopreventive agents and oxidative stress. Mol Cell Biol. 2003;23:8137-51.

[21] Kobayashi M, Li L, Iwamoto N, Nakajima-Takagi Y, Kaneko H, Nakayama Y, et al. The antioxidant defense system Keap1-Nrf2 comprises a multiple sensing mechanism for responding to a wide range of chemical compounds. Mol Cell Biol. 2009;29:493-502.

[22] Lozanovski VJ, Houben P, Hinz U, Hackert T, Herr I, Schemmer P. Pilot study evaluating broccoli sprouts in advanced pancreatic cancer (POUDER trial) - study protocol for a randomized controlled trial. Trials. 2014;15:204.

[23] Mirmiran P, Bahadoran Z, Hosseinpanah F, Keyzad A, Azizi F. Effects of broccoli sprout with high sulforaphane concentration on inflammatory markers in type 2 diabetic patients: A randomized double-blind placebo-controlled clinical trial. Journal of Functional Foods. 2012;4:837-41. 
[24] Morroni F, Tarozzi A, Sita G, Bolondi C, Zolezzi Moraga JM, Cantelli-Forti G, et al. Neuroprotective effect of sulforaphane in 6-hydroxydopamine-lesioned mouse model of Parkinson's disease. Neurotoxicology. 2013;36:63-71.

[25] Singh K, Connors SL, Macklin EA, Smith KD, Fahey JW, Talalay P, et al. Sulforaphane treatment of autism spectrum disorder (ASD). Proc Natl Acad Sci U S A. 2014;111:15550-5.

[26] Tufekci KU, Civi Bayin E, Genc S, Genc K. The Nrf2/ARE Pathway: A Promising Target to Counteract Mitochondrial Dysfunction in Parkinson's Disease. Parkinsons Dis. 2011;2011:314082.

[27] Abed DA, Goldstein M, Albanyan H, Jin H, Hu L. Discovery of direct inhibitors of Keap1-Nrf2 protein-protein interaction as potential therapeutic and preventive agents. Acta Pharm Sin B. 2015;5:285-99.

[28] Cheung KL, Kong AN. Molecular targets of dietary phenethyl isothiocyanate and sulforaphane for cancer chemoprevention. AAPS J. 2010;12:87-97.

[29] Durham A, Jazrawi E, Rhodes JA, Williams C, Kilty I, Barnes P, et al. The antiinflammatory effects of sulforaphane are not mediated by the Nrf2 pathway. Eur Respir J. 2014;44.

[30] Greaney AJ, Maier NK, Leppla SH, Moayeri M. Sulforaphane inhibits multiple inflammasomes through an Nrf2-independent mechanism. J Leukoc Biol. 2016;99:18999.

[31] Jo C, Gundemir S, Pritchard S, Jin YN, Rahman I, Johnson GV. Nrf2 reduces levels of phosphorylated tau protein by inducing autophagy adaptor protein NDP52. Nat Commun. 2014;5:3496.

[32] Yanaka A. Adaptive cytoprotection and cancer chemoprotection by sulforaphane against various stresses: role of nrf2-keap1 dependent and independent pathways (1052.1). The FASEB Journal. 2014;28.

[33] Wells G. Peptide and small molecule inhibitors of the Keap1-Nrf2 protein-protein interaction. Biochem Soc Trans. 2015;43:674-9.

[34] Fukutomi T, Takagi K, Mizushima T, Ohuchi N, Yamamoto M. Kinetic, thermodynamic, and structural characterizations of the association between Nrf2-DLGex degron and Keap1. Mol Cell Biol. 2014;34:832-46.

[35] Lo SC, Li X, Henzl MT, Beamer LJ, Hannink M. Structure of the Keap1:Nrf2 interface provides mechanistic insight into Nrf2 signaling. EMBO J. 2006;25:3605-17.

[36] Tong KI, Padmanabhan B, Kobayashi A, Shang C, Hirotsu Y, Yokoyama S, et al. Different electrostatic potentials define ETGE and DLG motifs as hinge and latch in oxidative stress response. Mol Cell Biol. 2007;27:7511-21.

[37] Chen Y, Inoyama D, Kong AN, Beamer LJ, Hu L. Kinetic analyses of Keap1-Nrf2 interaction and determination of the minimal Nrf2 peptide sequence required for Keap1 binding using surface plasmon resonance. Chem Biol Drug Des. 2011;78:1014-21.

[38] Hancock R, Bertrand HC, Tsujita T, Naz S, El-Bakry A, Laoruchupong J, et al. Peptide inhibitors of the Keap1-Nrf2 protein-protein interaction. Free Radic Biol Med. 2012;52:44451.

[39] Lu M-C, Chen Z-Y, Wang Y-L, Jiang Y-L, Yuan Z-W, You Q-D, et al. Binding thermodynamics and kinetics guided optimization of potent Keap1-Nrf2 peptide inhibitors. RSC Adv. 2015;5:85983-7.

[40] Hancock R, Schaap M, Pfister H, Wells G. Peptide inhibitors of the Keap1-Nrf2 protein-protein interaction with improved binding and cellular activity. Org Biomol Chem. 2013;11:3553-7.

[41] Steel R, Cowan J, Payerne E, O'Connell MA, Searcey M. Anti-inflammatory effect of a cell-penetrating peptide targeting the Nrf2/Keap1 interaction. ACS Med Chem Lett. 2012;3:407-10. 
[42] Hu L, Magesh S, Chen L, Wang L, Lewis TA, Chen Y, et al. Discovery of a smallmolecule inhibitor and cellular probe of Keap1-Nrf2 protein-protein interaction. Bioorg Med Chem Lett. 2013;23:3039-43.

* Description of one of the first small molecule Keap1-Nrf2 protein-protein interaction inhibitors to be described.

[43] Wen X, Thorne G, Hu L, Joy MS, Aleksunes LM. Activation of NRF2 Signaling in HEK293 Cells by a First-in-Class Direct KEAP1-NRF2 Inhibitor. J Biochem Mol Toxicol. 2015;29:261-6.

[44] Jnoff E, Albrecht C, Barker JJ, Barker O, Beaumont E, Bromidge S, et al. Binding mode and structure-activity relationships around direct inhibitors of the Nrf2-Keap1 complex. ChemMedChem. 2014;9:699-705.

[45] Marcotte D, Zeng W, Hus JC, McKenzie A, Hession C, Jin P, et al. Small molecules inhibit the interaction of Nrf2 and the Keap1 Kelch domain through a non-covalent mechanism. Bioorg Med Chem. 2013;21:4011-9.

[46] Jiang ZY, Lu MC, Xu LL, Yang TT, Xi MY, Xu XL, et al. Discovery of potent Keap1Nrf2 protein-protein interaction inhibitor based on molecular binding determinants analysis. J Med Chem. 2014;57:2736-45.

[47] Jain AD, Potteti H, Richardson BG, Kingsley L, Luciano JP, Ryuzoji AF, et al. Probing the structural requirements of non-electrophilic naphthalene-based Nrf2 activators. Eur $\mathrm{J}$ Med Chem. 2015;103:252-68.

[48] Jiang ZY, Xu LL, Lu MC, Chen ZY, Yuan ZW, Xu XL, et al. Structure-Activity and Structure-Property Relationship and Exploratory in Vivo Evaluation of the Nanomolar Keap1-Nrf2 Protein-Protein Interaction Inhibitor. J Med Chem. 2015;58:6410-21.

[49] Winkel AF, Engel CK, Margerie D, Kannt A, Szillat H, Glombik $H$, et al. Characterization of RA839, a Noncovalent Small Molecule Binder to Keap1 and Selective Activator of Nrf2 Signaling. J Biol Chem. 2015;290:28446-55.

[50] Lu MC, Ji JA, Jiang YL, Chen ZY, Yuan ZW, You QD, et al. An inhibitor of the Keap1Nrf2 protein-protein interaction protects NCM460 colonic cells and alleviates experimental colitis. Sci Rep. 2016;6:26585.

[51] Davies TG, Wixted WE, Coyle JE, Griffiths-Jones C, Hearn K, McMenamin R, et al. Monoacidic Inhibitors of the Kelch-like ECH-Associated Protein 1: Nuclear Factor Erythroid 2-Related Factor 2 (KEAP1:NRF2) Protein-Protein Interaction with High Cell Potency Identified by Fragment-Based Discovery. J Med Chem. 2016;59:3991-4006.

** This article describes the development of high affinity Keap1 lead compounds with potential applications in COPD.

[52] Shimozono R, Asaoka Y, Yoshizawa Y, Aoki T, Noda H, Yamada M, et al. Nrf2 activators attenuate the progression of nonalcoholic steatohepatitis-related fibrosis in a dietary rat model. Mol Pharmacol. 2013;84:62-70.

[53] Satoh M, Saburi H, Tanaka T, Matsuura Y, Naitow H, Shimozono R, et al. Multiple binding modes of a small molecule to human Keap1 revealed by X-ray crystallography and molecular dynamics simulation. FEBS Open Bio. 2015;5:557-70.

[54] East DA, Fagiani F, Crosby J, Georgakopoulos ND, Bertrand H, Schaap M, et al. PMl: A $\Delta \Psi \mathrm{m}$ independent pharmacological regulator of mitophagy. Chem Biol. 2014;21:158596.

* This article describes the role of Nrf2 inducing compounds in the regulation of mitophagy, suggesting potential therapeutic applications in neurodegenerative diseases.

[55] Redmann M, Dodson M, Boyer-Guittaut M, Darley-Usmar V, Zhang J. Mitophagy mechanisms and role in human diseases. Int J Biochem Cell Biol. 2014;53:127-33.

[56] Narendra D, Tanaka A, Suen D-F, Youle RJ. Parkin-induced mitophagy in the pathogenesis of Parkinson disease. Autophagy. 2014;5:706-8. 
[57] Zhang DD. Bardoxolone brings Nrf2-based therapies to light. Antioxid Redox Signal. 2013;19:517-8.

\section{Figure 1}

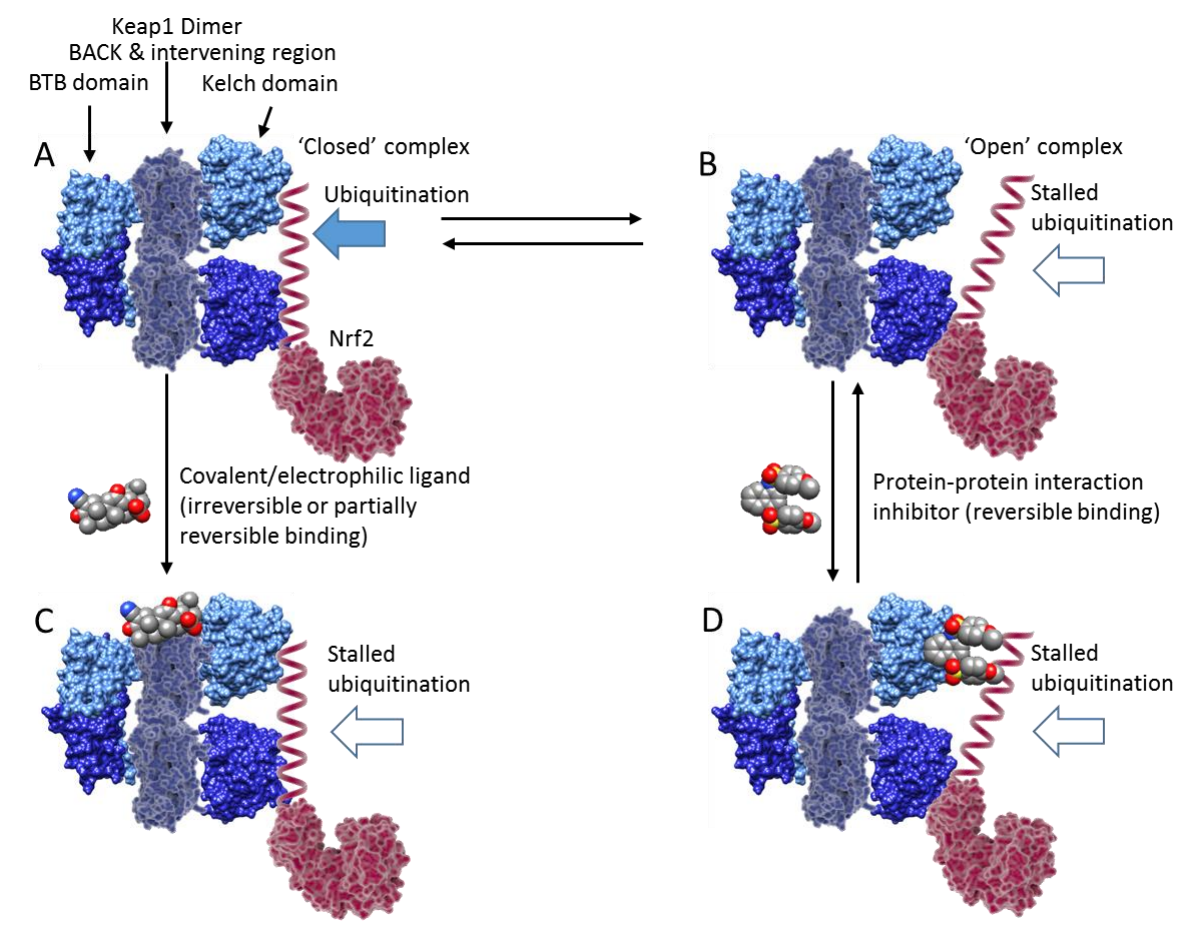


Figure 2

A.
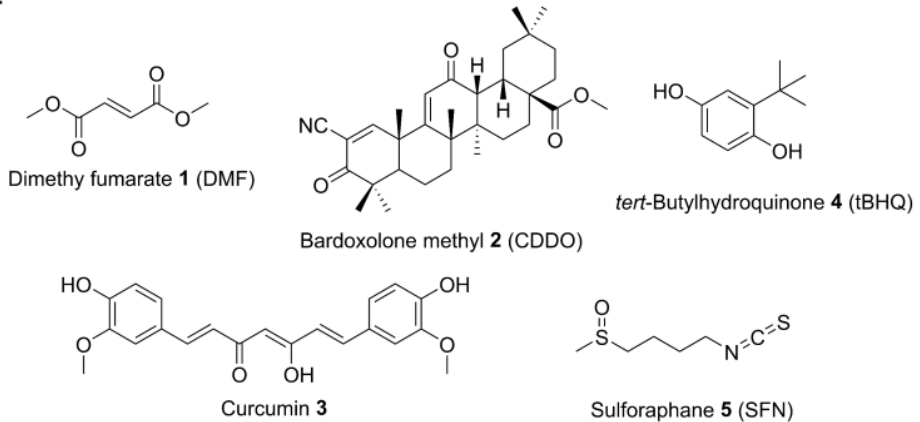

B.

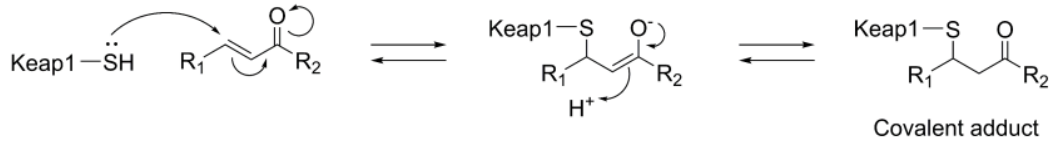

C.

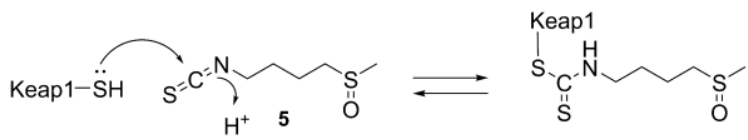


Figure 3A

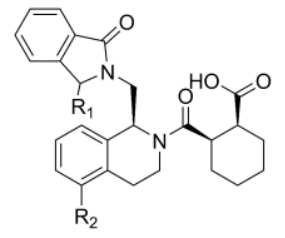

6: $\mathrm{R}_{1}=\mathrm{CO}, \mathrm{R}_{2}=\mathrm{H}$
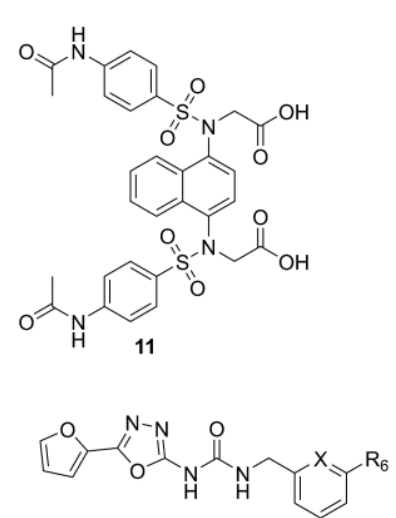

14: $\mathrm{X}=\mathrm{CH}, \mathrm{R}_{6}=\mathrm{OCH}_{2} \mathrm{COOH}$

15: $X=N, R_{6}=H$

Figure 3B,C,D

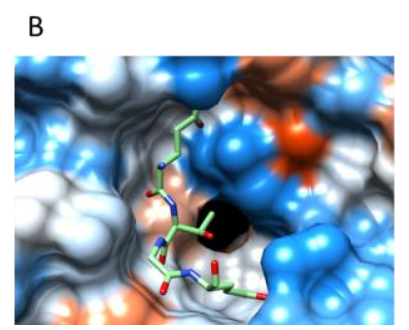

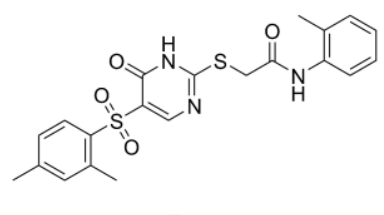

7
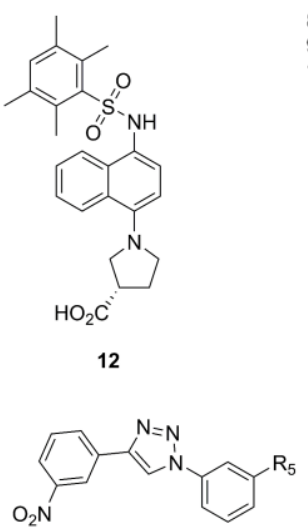

16: $\mathrm{R}_{5}=\mathrm{COOH}$

17: $R_{5}=1$

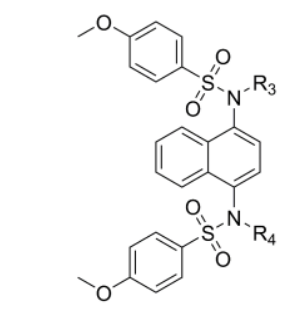

8: $\mathrm{R}_{2}=\mathrm{H}, \mathrm{R}_{3}=\mathrm{H}$

9: $\mathrm{R}_{2}=\mathrm{CH}_{2} \mathrm{COOH}, \mathrm{R}_{3}=\mathrm{CH}_{2} \mathrm{COOH}$

10: $\mathrm{R}_{2}=\mathrm{CH}_{2} \mathrm{CONH}_{2}, \mathrm{R}_{3}=\mathrm{CH}_{2} \mathrm{CONH}_{2}$

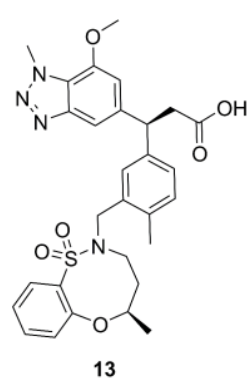

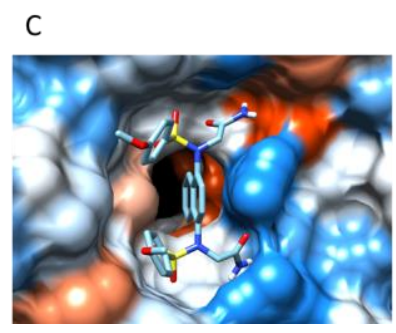

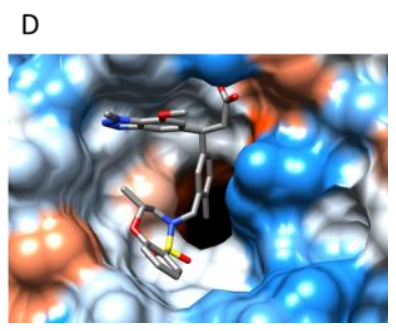




\section{Graphical Abstract}

Electrophilic and non-electrophilic Keap1-

interactive Nrf2 inducers
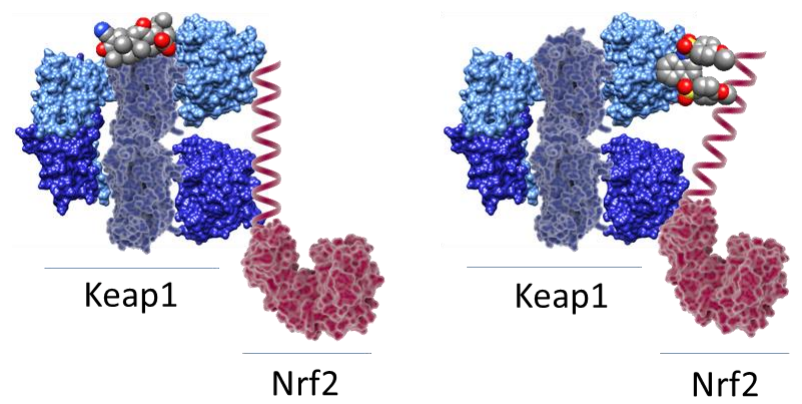